\title{
Common fixed point theorems for dominating and weak annihilator mappings in ordered metric spaces
}

\author{
Wasfi Shatanawi ${ }^{1}$ and Mihai Postolache ${ }^{2 *}$
}

\author{
${ }^{*}$ Correspondence: \\ mihai@mathem.pub.ro \\ ${ }^{2}$ Faculty of Applied Sciences, \\ University Politehnica of Bucharest, \\ 313 Splaiul Independenţei, \\ Bucharest, 060042, Romania \\ Full list of author information is \\ available at the end of the article
}

\begin{abstract}
Very recently, Haghi et al. (Topol. Appl. 160:450-454, 2013) proved that some fixed point theorems in partial metric spaces can be obtained from metric spaces. In this paper, we prove some common fixed point theorems for four mappings $f, g, S$ and $T$ satisfying a nonlinear contraction in ordered metric spaces, where the mappings $f$ and $g$ are dominating and weak annihilators of the mappings $T$ and $S$, respectively. We utilize the techniques of Haghi et al. to derive our main result, which is a generalization of the result of Shobkolaei et al. (Appl. Math. Comput. 219:443-452, 2012). Also, we introduce an example to support the usability of our results.

MSC: Primary $54 \mathrm{H} 25$; secondary $47 \mathrm{H} 10$

Keywords: partial metric space; common fixed point; altering distance function; almost contraction; ordered metric space
\end{abstract}

\section{Introduction}

One of the most important problems in mathematical analysis is to establish existence and uniqueness theorems for some integral and differential equations. Fixed point theory, in ordered metric spaces, plays a major role in solving such kind of problems. The first result in this direction was obtained by Ran and Reurings [1]. This one was extended for nondecreasing mappings by Nieto and Lopez [2, 3]. Meanwhile, Agarwal et al. [5] and O'Regan and Petruşel [4] studied some results for generalized contractions in ordered metric spaces. Then, many authors obtained fixed point results in ordered metric spaces. For some works in ordered metric spaces, we refer the reader to [6-19].

Berinde [20-24] initiated the concept of almost contraction and studied existence fixed point results for almost contraction in complete metric spaces. Later, many authors studied different types of almost contractions and studied fixed point results; for example, see [25-31].

In 1994 Matthews [32] introduced the concept of partial metric spaces and proved the Banach contraction principle in these spaces. Then, many authors obtained interesting results in partial metric spaces [33, 36-38]. Very recently, Haghi et al. [33] proved that some fixed point theorems in partial metric spaces can be obtained from metric spaces.

The purpose of this paper is to prove some common fixed point theorems for four mappings $f, g, S$ and $T$ satisfying a nonlinear contraction in ordered metric spaces, where the

\section{Springer}

(c)2013 Shatanawi and Postolache; licensee Springer. This is an Open Access article distributed under the terms of the Creative Commons Attribution License (http://creativecommons.org/licenses/by/2.0), which permits unrestricted use, distribution, and reproduction in any medium, provided the original work is properly cited. 
mappings $f$ and $g$ are dominating and weak annihilators of the mappings $T$ and $S$, respectively. We utilize the results of Haghi et al. [33] to derive Theorem 2.1.

\section{Previous notations and results}

In the sequel, we have to recall previous notations and results.

Let $f$ and $g$ be self-mappings of a set $X$. If $w=f x=g x$ for some $x \in X$, then $x$ is called a coincidence point of $f$ and $g$, and $w$ is called a point of coincidence of $f$ and $g$. Two selfmappings $f$ and $g$ are said to be weakly compatible if they commute at their coincidence point, that is, if $f x=g x$, then $f g x=g f x$. For details, please see [34].

Now, consider $(X, \preceq)$ to be a partially ordered set. According to [35], a mapping $f$ is called weak annihilator of $g$ if $f g x \preceq x$ for all $x \in X$ and $f$ is called dominating if $x \preceq f x$ for all $x \in X$.

Recently, Shobkolaei et al. [38] initiated the concept of almost generalized $(S, T)$ contractive condition in a partial metric space and studied some common fixed point results in partial metric spaces.

Definition 2.1 [38] Let $f, g, S$ and $T$ be self-maps on a partial metric space $(X, p)$. Then $f$ and $g$ are said to satisfy almost generalized $(S, T)$-contractive condition if there exists $\delta \in[0,1)$ such that

$$
p(f x, g y) \leq \delta \max \left\{p(S x, T y), p(f x, S x), p(g y, T y), \frac{p(S x, g y)+p(f x, T y)}{2}\right\}
$$

for all $x, y \in X$.

Theorem 2.1 [38] Let $(X, p, \preceq)$ be a complete ordered partial metric space. Let $f, g, T$, $S: X \rightarrow X$ be mappings with $f X \subseteq T X$ and $g X \subseteq S X$, and the dominating mappings $f$ and $g$ are weak annihilators of $T$ and $S$, respectively. Suppose that $f$ and $g$ satisfy almost generalized $(S, T)$-contractive condition (2.1) for any two comparable elements $x, y \in X$. If for a nondecreasing sequence $\left\{x_{n}\right\}$ with $x_{n} \preceq y_{n}$ for all $n$ but finitely many and $y_{n} \rightarrow u$ implies that $x_{n} \preceq u$, and furthermore

(1) $\{f, S\}$ and $\{g, T\}$ are weakly compatible;

(2) one of $f X, g X, S X$ and $T X$ is a closed subspace of $X$,

then $f, g, S$ and $T$ have a common fixed point.

Moreover, the set of common fixed points off, $g, S$ and $T$ is well ordered if and only iff, $g, S$ and $T$ have one and only one common fixed point.

\section{Main result}

Let $\Psi$ denote all functions $\psi:[0,+\infty) \rightarrow[0,+\infty)$ such that

(1) $\psi$ is continuous and nondecreasing;

(2) $\psi(t)=0$ if and only if $t=0$.

Also, let $\Phi$ denote all functions $\phi:[0,+\infty) \times[0,+\infty) \times[0,+\infty) \rightarrow[0,+\infty)$ such that

(1) $\phi$ is continuous;

(2) $\phi(t, s, u)=0$ if and only if $u=s=t=0$.

If $\psi \in \Psi$, then $\psi$ is called an altering distance function (see [39]).

Now, we introduce our definition. 
Definition 3.1 Let $f, g, S$ and $T$ be self-mappings on a metric space $(X, d)$. Then $f$ and $g$ are said to satisfy the almost nonlinear $(S, T, L, \psi, \phi)$-contractive condition if there exist $\psi \in \Psi, \phi \in \Phi$ and $L \in[0,+\infty)$ such that

$$
\begin{aligned}
\psi(d(f x, g y)) \leq & \psi\left(\max \left\{d(S x, T y), d(f x, S x), d(g y, T y), \frac{1}{2}(d(S x, g y)+d(f x, T y))\right\}\right) \\
& -\phi(d(S x, T y), d(S x, g y), d(f x, T y)) \\
& +L \min \{d(S x, T y), d(S x, g y), d(f x, T y)\}
\end{aligned}
$$

for all $x, y \in X$.

Now, let $(X, d, \preceq)$ be an ordered metric space. We say that $X$ satisfies the property $(\pi)$ if the following statement holds true.

( $\pi)$ If $\left\{x_{n}\right\}$ is a nondecreasing sequence in $X$ and $\left\{y_{n}\right\}$ is a sequence in $X$ such that $x_{n} \preceq y_{n}$ for all $n$ but finitely many and $y_{n} \rightarrow u$, then $x_{n} \preceq u$ for all $n$ but finitely many.

In the rest of this paper, $\mathbb{N}$ stands for the set of nonnegative integer numbers.

Theorem 3.1 Let $(X, d, \preceq)$ be a complete ordered metric space. Let $f, g, T, S: X \rightarrow X$ be four mappings such that $f$ and $g$ satisfy the nonlinear $(S, T, L, \psi, \phi)$-contractive condition (3.1) for any two comparable elements $x, y \in X$. Suppose that $f, g, S$ and $T$ satisfy the following conditions:

(1) $f X \subseteq T X$;

(2) $g X \subseteq S X$;

(3) $L a-\phi(a, a, a)<0$ for all $a>0$;

(4) $f$ is dominating and weak annihilator of $T$;

(5) $g$ is dominating and weak annihilator of $S$;

(6) $\{f, S\}$ and $\{g, T\}$ are weakly compatible;

(7) one of $f X, g X, S X$ and $T X$ is a closed subspace of $X$.

If $X$ has the property $(\pi)$, then $f, g, S$ and $T$ have a common fixed point.

Proof Let $x_{0} \in X$. Since $f X \subseteq T X$, we choose $x_{1} \in X$ such that $f x_{0}=T x_{1}$. Also, since $g X \subseteq S X$, we choose $x_{2} \in X$ such that $g x_{1}=S x_{2}$. Continuing this process, we can construct a sequence $\left\{y_{n}\right\}$ in $X$ such $y_{2 n}:=f x_{2 n}=T x_{2 n+1}$ and $y_{2 n+1}:=g x_{2 n+1}=S x_{2 n+2}$. Since $f$ is dominating and weak annihilator of $T$ and $g$ is dominating and weak annihilator of $S$,

$$
x_{2 n} \preceq f x_{2 n}=T x_{2 n+1} \preceq f T x_{2 n+1} \preceq x_{2 n+1} \preceq g x_{2 n+1}=S x_{2 n+2} \preceq g S x_{2 n+2} \preceq x_{2 n+2} .
$$

Thus, for all $n \geq 0$, we have $x_{n} \preceq x_{n+1}$.

Suppose $y_{2 n}=y_{2 n+1}$ for some $n \in \mathbb{N}$. We claim that $y_{2 n+1}=y_{2 n+2}$. Since $x_{2 n+2}$ and $x_{2 n+3}$ are comparable, we have

$$
\begin{aligned}
& \psi\left(d\left(y_{2 n+2}, y_{2 n+1}\right)\right) \\
& \quad=\psi\left(d\left(f x_{2 n+2}, g x_{2 n+1}\right)\right) \\
& \quad \leq \psi\left(\operatorname { m a x } \left\{d\left(S x_{2 n+2}, T x_{2 n+1}\right), d\left(f x_{2 n+2}, S x_{2 n+2}\right), d\left(g x_{2 n+1}, T x_{2 n+1}\right),\right.\right.
\end{aligned}
$$




$$
\begin{aligned}
& \left.\left.\frac{1}{2}\left(d\left(S x_{2 n+2}, g x_{2 n+1}\right)+d\left(f x_{2 n+2}, T x_{2 n+1}\right)\right)\right\}\right) \\
& -\phi\left(d\left(S x_{2 n+2}, T x_{2 n+1}\right), d\left(S x_{2 n+2}, g x_{2 n+1}\right), d\left(f x_{2 n+2}, T x_{2 n+1}\right)\right) \\
& +L \min \left\{d\left(S x_{2 n+2}, T x_{2 n+1}\right), d\left(S x_{2 n+2}, g x_{2 n+1}\right), d\left(f x_{2 n+2}, T x_{2 n+1}\right)\right\} \\
= & \psi\left(\operatorname { m a x } \left\{d\left(y_{2 n+1}, y_{2 n}\right), d\left(y_{2 n+2}, y_{2 n+1}\right), d\left(y_{2 n+1}, y_{2 n}\right),\right.\right. \\
& \left.\left.\frac{1}{2}\left(d\left(y_{2 n+1}, y_{2 n+1}\right)+d\left(y_{2 n+2}, y_{2 n}\right)\right)\right\}\right)-\phi\left(d\left(y_{2 n+1}, y_{2 n}\right), d\left(y_{2 n+1}, y_{2 n+1}\right), d\left(y_{2 n+2}, y_{2 n}\right)\right) \\
& +L \min \left\{d\left(y_{2 n+1}, y_{2 n}\right), d\left(y_{2 n+1}, y_{2 n+1}\right), d\left(y_{2 n+2}, y_{2 n}\right)\right\} \\
= & \psi\left(\max \left\{0, d\left(y_{2 n+2}, y_{2 n+1}\right), \frac{1}{2}\left(d\left(y_{2 n+2}, y_{2 n+1}\right)\right)\right\}\right)-\phi\left(0,0, d\left(y_{2 n+2}, y_{2 n+1}\right)\right) \\
= & \psi\left(d\left(y_{2 n+2}, y_{2 n+1}\right)\right)-\phi\left(0,0, d\left(y_{2 n+2}, y_{2 n+1}\right)\right) \\
\leq & \psi\left(d\left(y_{2 n+2}, y_{2 n+1}\right)\right) .
\end{aligned}
$$

Therefore, $\phi\left(0,0, d\left(y_{2 n+2}, y_{2 n+1}\right)\right)=0$ and hence $y_{2 n+2}=y_{2 n+1}$. Similarly, we may show that $y_{2 n+3}=y_{2 n+2}$. Thus $\left\{y_{n}\right\}$ is a constant sequence in $X$, hence it is a Cauchy sequence in $(X, d)$.

Suppose $y_{2 n} \neq y_{2 n+1}$ for all $n \in \mathbb{N}$. Given $n \in \mathbb{N}$. If $n$ is even, then $n=2 t$ for some $t \in \mathbb{N}$. Since $x_{2 t}$ and $x_{2 t+1}$ are comparable, we have

$$
\begin{aligned}
\psi( & \left.d\left(y_{n}, y_{n+1}\right)\right) \\
= & \psi\left(d\left(y_{2 t}, y_{2 t+1}\right)\right) \\
= & \psi\left(d\left(f x_{2 t}, g x_{2 t+1}\right)\right) \\
\leq & \psi\left(\operatorname { m a x } \left\{d\left(S x_{2 t}, T x_{2 t+1}\right), d\left(f x_{2 t}, S x_{2 t}\right), d\left(g x_{2 t+1}, T x_{2 t+1}\right)\right.\right. \\
& \left.\left.\frac{1}{2}\left(d\left(S x_{2 t}, g x_{2 t+1}\right)+d\left(f x_{2 t}, T x_{2 t+1}\right)\right)\right\}\right) \\
& -\phi\left(d\left(S x_{2 t}, T x_{2 t+1}\right), d\left(S x_{2 t}, g x_{2 t+1}\right), d\left(f x_{2 t}, T x_{2 t+1}\right)\right) \\
& +L \min \left\{d\left(S x_{2 t}, T x_{2 t+1}\right), d\left(S x_{2 t}, g x_{2 t+1}\right), d\left(f x_{2 t}, T x_{2 t+1}\right)\right\} \\
= & \left(\max \left\{d\left(y_{2 t-1}, y_{2 t}\right), d\left(y_{2 t}, y_{2 t+1}\right), \frac{1}{2}\left(d\left(y_{2 t-1}, y_{2 t+1}\right)\right)\right\}\right) \\
& -\phi\left(d\left(y_{2 t-1}, y_{2 t}\right), d\left(y_{2 t-1}, y_{2 t+1}\right), 0\right) \\
\leq & \psi\left(\max \left\{d\left(y_{2 t-1}, y_{2 t}\right), d\left(y_{2 t}, y_{2 t+1}\right), \frac{1}{2}\left(d\left(y_{2 t-1}, y_{2 t}\right)+d\left(y_{2 t}, y_{2 t+1}\right)\right)\right\}\right) \\
\leq & \phi\left(d\left(y_{2 t-1}, y_{2 t}\right), d\left(y_{2 t-1}, y_{2 t+1}\right), 0\right) \\
= & \psi\left(\max \left\{d\left(y_{2 t-1}, y_{2 t}\right), d\left(y_{2 t}, y_{2 t+1}\right)\right\}\right)-\phi\left(d\left(y_{2 t-1}, y_{2 t}\right), d\left(y_{2 t-1}, y_{2 t+1}\right), 0\right) \\
& \left.\left\{d\left(y_{2 t-1}, y_{2 t}\right), d\left(y_{2 t}, y_{2 t+1}\right)\right\}\right) . \\
&
\end{aligned}
$$

If

$$
\max \left\{d\left(y_{2 t-1}, y_{2 t}\right), d\left(y_{2 t}, y_{2 t+1}\right)\right\}=d\left(y_{2 t}, y_{2 t+1}\right),
$$


then

$$
\phi\left(d\left(y_{2 t-1}, y_{2 t}\right), d\left(y_{2 t-1}, y_{2 t+1}\right), 0\right)=0
$$

and hence $d\left(y_{2 t-1}, y_{2 t}\right)=d\left(y_{2 t-1}, y_{2 t+1}\right)=0$. Thus $y_{2 t-1}=y_{2 t}$, a contradiction.

Thus,

$$
\max \left\{d\left(y_{2 t-1}, y_{2 t}\right), d\left(y_{2 t}, y_{2 t+1}\right)\right\}=d\left(y_{2 t-1}, y_{2 t}\right) .
$$

Therefore,

$$
\psi\left(d\left(y_{2 t}, y_{2 t+1}\right)\right) \leq \psi\left(d\left(y_{2 t-1}, y_{2 t}\right)\right)-\phi\left(d\left(y_{2 t-1}, y_{2 t}\right), d\left(y_{2 t-1}, y_{2 t+1}\right), 0\right) .
$$

If $n$ is odd, then $n=2 t+1$ for some $t \in \mathbb{N}$. Since $x_{2 t+2}$ and $x_{2 t+1}$ are comparable, we have

$$
\begin{aligned}
\psi( & d\left(y_{n}, y_{n+1}\right) \\
=\psi & \left(d\left(y_{2 t+2}, y_{2 t+1}\right)\right) \\
=\psi & \left(d\left(f x_{2 t+2}, g x_{2 t+1}\right)\right) \\
\leq & \psi\left(\operatorname { m a x } \left\{d\left(S x_{2 t+2}, T x_{2 t+1}\right), d\left(f x_{2 t+2}, S x_{2 t+2}\right), d\left(g x_{2 t+1}, T x_{2 t+1}\right),\right.\right. \\
& \left.\left.\frac{1}{2}\left(d\left(S x_{2 t+2}, g x_{2 t+1}\right)+d\left(f x_{2 t+2}, T x_{2 t+1}\right)\right)\right\}\right) \\
& -\phi\left(d\left(S x_{2 t+2}, T x_{2 t+1}\right), d\left(S x_{2 t+2}, g x_{2 t+1}\right), d\left(f x_{2 t+2}, T x_{2 t+1}\right)\right) \\
& +L \min \left\{d\left(S x_{2 t+2}, T x_{2 t+1}\right), d\left(S x_{2 t+2}, g x_{2 t+1}\right), d\left(f x_{2 t+2}, T x_{2 t+1}\right)\right\} \\
= & \left(\max \left\{d\left(y_{2 t+1}, y_{2 t}\right), d\left(y_{2 t+2}, y_{2 t+1}\right), \frac{1}{2}\left(d\left(y_{2 t+2}, y_{2 t}\right)\right)\right\}\right) \\
& -\phi\left(d\left(y_{2 t+1}, y_{2 t}\right), 0, d\left(y_{2 t+2}, y_{2 t}\right)\right) \\
\leq & \psi\left(\max \left\{d\left(y_{2 t+1}, y_{2 t}\right), d\left(y_{2 t+2}, y_{2 t+1}\right), \frac{1}{2}\left(d\left(y_{2 t+2}, y_{2 t+1}\right)+d\left(d\left(y_{2 t+1}, y_{2 t}\right)\right)\right)\right\}\right) \\
& -\phi\left(d\left(y_{2 t+1}, y_{2 t}\right), 0, d\left(y_{2 t+2}, y_{2 t}\right)\right) \\
= & \psi\left(\max \left\{d\left(y_{2 t+1}, y_{2 t}\right), d\left(y_{2 t+2}, y_{2 t+1}\right)\right\}\right)-\phi\left(d\left(y_{2 t+1}, y_{2 t}\right), 0, d\left(y_{2 t+2}, y_{2 t}\right)\right) \\
\leq & \psi\left(\max \left\{d\left(y_{2 t+1}, y_{2 t}\right), d\left(y_{2 t+2}, y_{2 t+1}\right)\right\}\right) .
\end{aligned}
$$

If

$\max \left\{d\left(y_{2 t+1}, y_{2 t}\right), d\left(y_{2 t+2}, y_{2 t+1}\right)\right\}=d\left(y_{2 t+2}, y_{2 t+1}\right)$,

then

$$
\phi\left(d\left(y_{2 t+1}, y_{2 t}\right), 0, d\left(y_{2 t+2}, y_{2 t}\right)\right)=0,
$$

and hence $d\left(y_{2 t+1}, y_{2 t}\right)=d\left(y_{2 t+2}, y_{2 t}\right)=0$. Thus $y_{2 t+1}=y_{2 t}$, a contradiction. So,

$$
\max \left\{d\left(y_{2 t+1}, y_{2 t}\right), d\left(y_{2 t+2}, y_{2 t+1}\right)\right\}=d\left(y_{2 t+1}, y_{2 t}\right) .
$$


Therefore

$$
\psi\left(d\left(y_{2 t+2}, y_{2 t+1}\right)\right) \leq \psi\left(d\left(y_{2 t+1}, y_{2 t}\right)\right)-\phi\left(d\left(y_{2 t+1}, y_{2 t}\right), 0, d\left(y_{2 t+2}, y_{2 t}\right)\right) .
$$

From (3.2) and (3.4), we have

$$
d\left(y_{n}, y_{n+1}\right) \leq d\left(y_{n-1}, y_{n}\right) .
$$

Therefore $\left\{d\left(y_{n+1}, y_{n}\right): n \in \mathbb{N}\right\}$ is a nonincreasing sequence. Thus there exists $r \geq 0$ such that

$$
\lim _{n \rightarrow+\infty} d\left(y_{n}, y_{n+1}\right)=r
$$

On taking lim sup in (3.3) and (3.5), we have

$$
\psi(r) \leq \psi(r)-\liminf _{t \rightarrow+\infty} \phi\left(d\left(y_{2 t-1}, y_{2 t}\right), d\left(y_{2 t-1}, y_{2 t+1}\right), 0\right)
$$

and

$$
\psi(r) \leq \psi(r)-\liminf _{t \rightarrow+\infty} \phi\left(d\left(y_{2 t+1}, y_{2 t}\right), 0, d\left(y_{2 t}, y_{2 t+2}\right)\right) .
$$

Thus

$$
\liminf _{t \rightarrow+\infty} d\left(y_{2 t-1}, y_{2 t}\right)=\liminf _{t \rightarrow+\infty} d\left(y_{2 t-1}, y_{2 t+1}\right)=\liminf _{t \rightarrow+\infty} d\left(y_{2 t}, y_{2 t+2}\right)=\liminf _{t \rightarrow+\infty} d\left(y_{2 t}, y_{2 t+1}\right)=0 .
$$

Therefore, $r=0$ and hence

$$
\lim _{n \rightarrow+\infty} d\left(y_{n}, y_{n+1}\right)=0
$$

Now, we show that $\left\{y_{n}\right\}$ is a Cauchy sequence in the metric space $(X, d)$. It is sufficient to show that $\left\{y_{2 n}\right\}$ is a Cauchy sequence in $(X, d)$. Suppose to the contrary; that is, $\left\{y_{2 n}\right\}$ is not a Cauchy sequence in $(X, d)$. Then there exists $\epsilon>0$ for which we can find two subsequences $\left\{y_{2 m(i)}\right\}$ and $\left\{y_{2 n(i)}\right\}$ of $\left\{y_{2 n}\right\}$ such that $n(i)$ is the smallest index for which

$$
n(i)>m(i)>i, \quad d\left(y_{2 m(i)}, y_{2 n(i)}\right) \geq \epsilon
$$

and

$$
d\left(y_{2 m(i)}, y_{2 n(i)-2}\right)<\epsilon .
$$

From (3.8), (3.9) and the triangular inequality, we get that

$$
\begin{aligned}
\epsilon & \leq d\left(y_{2 m(i)}, y_{2 n(i)}\right) \\
& \leq d\left(y_{2 m(i)}, y_{2 n(i)-2}\right)+d\left(y_{2 n(i)-2}, y_{2 n(i)-1}\right)+d\left(y_{2 n(i)-1}, y_{2 n(i)}\right) \\
& <\epsilon+d\left(y_{2 n(i)-2}, y_{2 n(i)-1}\right)+d\left(y_{2 n(i)-1}, y_{2 n(i)}\right) .
\end{aligned}
$$


On letting $i \rightarrow+\infty$ in the above inequalities and using (3.7), we have

$$
\lim _{i \rightarrow+\infty} d\left(y_{2 m(i)}, y_{2 n(i)}\right)=\epsilon
$$

Again, from (3.8) and the triangular inequality, we get that

$$
\begin{aligned}
\epsilon & \leq d\left(y_{2 m(i)}, y_{2 n(i)}\right) \\
& \leq d\left(y_{2 n(i)}, y_{2 n(i)-1}\right)+d\left(y_{2 n(i)-1}, y_{2 m(i)}\right) \\
& \leq d\left(y_{2 n(i)}, y_{2 n(i)-1}\right)+d\left(y_{2 n(i)-1}, y_{2 m(i)+1}\right)+d\left(y_{2 m(i)+1}, y_{2 m(i)}\right) \\
& \leq d\left(y_{2 n(i)}, y_{2 n(i)-1}\right)+d\left(y_{2 n(i)-1}, y_{2 m(i)}\right)+2 d\left(y_{2 m(i)+1}, y_{2 m(i)}\right) \\
& \leq 2 d\left(y_{2 n(i)}, y_{2 n(i)-1}\right)+d\left(y_{2 n(i)}, y_{2 m(i)}\right)+2 d\left(y_{2 m(i)+1}, y_{2 m(i)}\right) .
\end{aligned}
$$

Letting $i \rightarrow+\infty$ in the above inequalities and using (3.7) and (3.10), we get that

$$
\begin{aligned}
\lim _{i \rightarrow+\infty} d\left(y_{2 m(i)}, y_{2 n(i)}\right) & =\lim _{i \rightarrow+\infty} d\left(y_{2 m(i)+1}, y_{2 n(i)-1}\right) \\
& =\lim _{i \rightarrow+\infty} d\left(y_{2 m(i)+1}, y_{2 n(i)}\right) \\
& =\lim _{i \rightarrow+\infty} d\left(y_{2 m(i)}, y_{2 n(i)-1}\right) \\
& =\epsilon .
\end{aligned}
$$

Since $x_{2 n(i)}$ and $x_{2 m(i)+1}$ are comparable, we have

$$
\begin{aligned}
\psi( & \left.d\left(y_{2 n(i)}, y_{2 m(i)+1}\right)\right) \\
=\psi & \left(d\left(f x_{2 n(i)}, g x_{2 m(i)+1}\right)\right) \\
\leq & \psi\left(\operatorname { m a x } \left\{d\left(S x_{2 n(i)}, T x_{2 m(i)+1}\right), d\left(f x_{2 n(i)}, S x_{2 n(i)}\right), d\left(g x_{2 m(i)+1}, T x_{2 m(i)+1}\right)\right.\right. \\
& \left.\left.\frac{1}{2}\left(d\left(S x_{2 n(i)}, g x_{2 m(i)+1}\right)+d\left(f x_{2 n(i)}, T x_{2 m(i)+1}\right)\right)\right\}\right) \\
& -\phi\left(d\left(S x_{2 n(i)}, T x_{2 m(i)+1}\right), d\left(S x_{2 n(i)}, g x_{2 m(i)+1}\right), d\left(f x_{2 n(i)}, T x_{2 m(i)+1}\right)\right) \\
& +L \min \left\{d\left(S x_{2 n(i)}, T x_{2 m(i)+1}\right), d\left(S x_{2 n(i)}, g x_{2 m(i)+1}\right), d\left(f x_{2 n(i)}, T x_{2 m(i)+1}\right)\right\} \\
= & \left(\operatorname { m a x } \left\{d\left(y_{2 n(i)-1}, y_{2 m(i)}\right), d\left(y_{2 n(i)}, y_{2 n(i)-1}\right), d\left(y_{2 m(i)+1}, y_{2 m(i)}\right)\right.\right. \\
& \left.\left.\frac{1}{2}\left(d\left(y_{2 n(i)}, y_{2 m(i)}\right)+d\left(y_{2 n(i)-1}, y_{2 m(i)+1}\right)\right)\right\}\right) \\
& -\phi\left(d\left(y_{2 n(i)-1}, y_{2 m(i)}\right), d\left(y_{2 n(i)-1}, y_{2 m(i)+1}\right), d\left(y_{2 n(i)}, y_{2 m(i)}\right)\right) \\
& +L \min \left\{d\left(y_{2 n(i)-1}, y_{2 m(i)}\right), d\left(y_{2 n(i)-1}, y_{2 m(i)+1}\right), d\left(y_{2 n(i)}, y_{2 m(i)}\right)\right\}
\end{aligned}
$$

Letting $i \rightarrow+\infty$ and using the continuity of $\psi$, we get that

$$
\psi(\epsilon) \leq \psi(\epsilon)-\phi(\epsilon, \epsilon, \epsilon)+L \epsilon
$$


By condition (3), we get $\psi(\epsilon)=0$ and hence $\epsilon=0$, a contradiction. Thus $\left\{y_{n}\right\}$ is a Cauchy sequence in $(X, d)$.

Since $(X, d)$ is complete, there is $y \in X$ such that $y_{n} \rightarrow y$ in the metric space $(X, d)$. Thus

$$
\lim _{n \rightarrow+\infty} d\left(y_{n}, y\right)=0
$$

Now we show that $y$ is the fixed point of $g$ and $T$. Assume that $T X$ is closed, since $\left\{y_{2 n}=\right.$ $\left.T x_{2 n+1}\right\}$ is a sequence in $T X$ converging to $y$, we have $y \in T X$. So, there exists $u \in X$ such that $y=T u$. Therefore,

$$
\lim _{n \rightarrow+\infty} f x_{2 n}=\lim _{n \rightarrow+\infty} g x_{2 n+1}=\lim _{n \rightarrow+\infty} T x_{2 n+1}=\lim _{n \rightarrow+\infty} S x_{2 n+2}=y=T u .
$$

Now, we show that $g u=y$. Since $x_{2 n} \preceq f x_{2 n}$ and $y_{2 n}=f x_{2 n} \rightarrow y$, we have $x_{2 n} \preceq y$. Since the mapping $f$ is dominating and weak annihilator of $T$, we obtain $x_{2 n} \preceq y=T u \preceq f T u \preceq u$. Thus

$$
\begin{aligned}
\psi( & \left(d\left(y_{2 n}, g u\right)\right) \\
= & \psi\left(d\left(f x_{2 n}, g u\right)\right) \\
\leq & \psi\left(\max \left\{d\left(S x_{2 n}, T u\right), d\left(f x_{2 n}, S x_{2 n}\right), d(g u, T u), \frac{1}{2}\left(d\left(S x_{2 n}, g u\right)+d\left(f x_{2 n}, T u\right)\right)\right\}\right) \\
& -\phi\left(d\left(S x_{2 n}, T u\right), d\left(S x_{2 n}, g u\right), d\left(f x_{2 n}, T u\right)\right) \\
& +L \min \left\{d\left(S x_{2 n}, T u\right), d\left(S x_{2 n}, g u\right), d\left(f x_{2 n}, T u\right)\right\} \\
= & \psi\left(\max \left\{d\left(y_{2 n-1}, y\right), d\left(y_{2 n}, y_{2 n-1}\right), d(g u, y), \frac{1}{2}\left(d\left(y_{2 n-1}, g u\right)+d\left(y_{2 n}, y\right)\right)\right\}\right) \\
& -\phi\left(d\left(y_{2 n-1}, y\right), d\left(y_{2 n-1}, g u\right), d\left(y_{2 n}, y\right)\right)+L \min \left\{d\left(y_{2 n-1}, y\right), d\left(y_{2 n-1}, g u\right), d\left(y_{2 n}, y\right)\right\} .
\end{aligned}
$$

Letting $n \rightarrow+\infty$ in the above inequalities and using (3.7), we get that

$$
\psi(d(y, g u)) \leq \psi(d(g u, y))-\phi(0, d(y, g u), 0)
$$

Therefore $\phi(0, d(y, g u), 0)=0$ and hence $d(g u, y)=0$. Thus $g u=y$. Since $g$ and $T$ are weakly compatible and $g u=g T u=T g u=T y$, we have

$$
g y=g T u=T g u=T y .
$$

Again, since $x_{2 n}$ and $y$ are comparable, we have

$$
\begin{aligned}
\psi( & \left.\left(y_{2 n}, g y\right)\right) \\
= & \psi\left(d\left(f x_{2 n}, g y\right)\right) \\
\leq & \psi\left(\max \left\{d\left(S x_{2 n}, T y\right), d\left(f x_{2 n}, S x_{2 n}\right), d(g y, T y), \frac{1}{2}\left(d\left(S x_{2 n}, g y\right)+d\left(f x_{2 n}, T y\right)\right)\right\}\right) \\
& \quad-\phi\left(d\left(S x_{2 n}, T y\right), d\left(S x_{2 n}, g y\right), d\left(f x_{2 n}, T y\right)\right) \\
& +L \min \left\{d\left(S x_{2 n}, T y\right), d\left(S x_{2 n}, g y\right), d\left(f x_{2 n}, T y\right)\right\}
\end{aligned}
$$




$$
\begin{aligned}
= & \psi\left(\max \left\{d\left(y_{2 n-1}, g y\right), d\left(y_{2 n}, y_{2 n-1}\right), d(g y, g y), \frac{1}{2}\left(d\left(y_{2 n-1}, g y\right)+d\left(y_{2 n}, g y\right)\right)\right\}\right) \\
& -\phi\left(d\left(y_{2 n-1}, g y\right), d\left(y_{2 n-1}, g y\right), d\left(y_{2 n}, g y\right)\right)+\min \left\{d\left(y_{2 n-1}, g y\right), d\left(y_{2 n-1}, g y\right), d\left(y_{2 n}, g y\right)\right\} .
\end{aligned}
$$

On letting $n \rightarrow+\infty$ in the above inequalities and using (3.7), we have

$$
\psi(d(y, g y)) \leq \psi(d(y, g y))-\phi(d(y, g y), d(y, g y), d(y, g y))+L d(y, g y) .
$$

Using condition (3), we get $\psi(d(y, g y))=0$. Thus $d(y, g y)=0$ and hence $g y=y$.

Finally, we have to show that $y$ is also a fixed point of $f$ and $T$. Since $g X \subseteq S X$, there exists $v \in X$ such that $y=g y=S v$. Since the mapping $g$ is dominating and weak annihilator of $S$, we have $y \preceq g y=S v \preceq g S v \preceq v$. Thus $y$ and $v$ are comparable, and hence

$$
\begin{aligned}
\psi( & d(f v, S v)) \\
= & \psi(d(f v, g y)) \\
\leq & \psi\left(\max \left\{d(S v, T y), d(f v, S v), d(g y, T y), \frac{1}{2}(d(S v, g y)+d(f v, T y))\right\}\right) \\
& -\phi(d(S v, T y), d(S v, g y), d(f v, T y))+L \min \{d(S v, T y), d(S v, g y), d(f v, T y)\} \\
= & \psi\left(\max \left\{d(S v, S v), d(f v, S v), d(S v, S v), \frac{1}{2}(d(S v, S v)+d(f v, S v))\right\}\right) \\
& -\phi(d(S v, S v), d(S v, S v), d(f v, S v))+L \min \{d(S v, S v), d(S v, S v), d(f v, S v)\} \\
= & \psi(d(f v, S v))-\phi(0,0, d(f v, S v))+L d(f v, S v) .
\end{aligned}
$$

Using condition (3), we get $\psi(d(f v, S v))=0$. Thus $d(f v, S v)=0$ and hence $f v=S v=g y=y$. Since $f$ and $S$ are weakly compatible, we have $f y=f S v=S f v=S y$. Since $y$ and $y$ are comparable, we have

$$
\begin{aligned}
\psi(d(f y, y)) \\
=\psi(d(f y, g y)) \\
\leq \psi\left(\max \left\{d(S y, T y), d(f y, S y), d(g y, T y), \frac{1}{2}(d(S y, g y)+d(f y, T y))\right\}\right) \\
\quad-\phi(d(S y, T y), d(S y, g y), d(f y, T y))+L \min \{d(S y, T y), d(S y, g y), d(f y, T y)\} \\
=\psi\left(\max \left\{d(f y, y), d(f y, f y), d(y, y), \frac{1}{2}(d(f y, y)+d(f y, y))\right\}\right) \\
\quad-\phi(d(f y, y), d(f y, y), d(f y, y))+L \min \{d(f y, y), d(f y, y), d(f y, y)\} \\
=\psi(d(f y, y))-\phi(d(f y, y), d(f y, y), d(f y, y))+L d(f y, y) .
\end{aligned}
$$

Using condition (3), we get $\psi(d(f y, y))=0$. Thus $d(f y, y)=0$ and hence $f y=y$. So, $y$ is a common fixed point of $f, g, T$ and $S$. In case $S X, f X$ or $g X$ is closed, the proof of the existence of a common fixed point is similar to the arguments above. 
Corollary 3.1 Let $(X, d, \preceq)$ be a complete ordered metric space, and let $f, g, T, S: X \rightarrow X$ be four mappings. Assume that there exist $\psi \in \Psi$ and $\phi \in \Phi$ such that

$$
\begin{aligned}
\psi(d(f x, g y)) \leq & \psi\left(\max \left\{d(S x, T y), d(f x, S x), d(g y, T y), \frac{1}{2}(d(S x, g y)+d(f x, T y))\right\}\right) \\
& -\phi(\max \{d(S x, T y), d(S x, g y), d(f x, T y)\})
\end{aligned}
$$

holds for any two comparable elements $x, y \in X$. Suppose that $f, g, S$ and $T$ satisfy the following conditions:

(1) $f X \subseteq T X$;

(2) $g X \subseteq S X$;

(3) $f$ is dominating and weak annihilator of $T$;

(4) $g$ is dominating and weak annihilator of $S$;

(5) $\{f, S\}$ and $\{g, T\}$ are weakly compatible;

(6) one of $f X, g X, S X$ and $T X$ is a closed subspace of $X$.

If $X$ satisfies the property $(\pi)$, then $f, g, S$ and $T$ have a common fixed point.

Corollary 3.2 Let $(X, d, \preceq)$ be a complete ordered metric space, and let $f, g, T, S: X \rightarrow X$ be four mappings. Assume that there exist $\phi_{1}, \psi \in \Psi$ such that

$$
\begin{aligned}
\psi(d(f x, g y)) \leq & \psi\left(\max \left\{d(S x, T y), d(f x, S x), d(g y, T y), \frac{1}{2}(d(S x, g y)+d(f x, T y))\right\}\right) \\
& -\phi_{1}(\max \{d(S x, T y), d(S x, g y), d(f x, T y)\})
\end{aligned}
$$

holds for any two comparable elements $x, y \in X$. Suppose that $f, g, S$ and $T$ satisfy the following conditions:

(1) $f X \subseteq T X$;

(2) $g X \subseteq S X$;

(3) $f$ is dominating and weak annihilator of $T$;

(4) $g$ is dominating and weak annihilator of $S$;

(5) $\{f, S\}$ and $\{g, T\}$ are weakly compatible;

(6) one of $f X, g X, S X$ and $T X$ is a closed subspace of $X$.

If $X$ satisfies the property $(\pi)$, then $f, g, S$ and $T$ have a common fixed point.

Proof Follows from Corollary 3.1 by defining $\phi:[0,+\infty) \times[0,+\infty) \times[0,+\infty) \rightarrow[0,+\infty)$ via $\phi(s, t, u)=\phi_{1}(\max \{s, t, u\})$ and noting that $\phi \in \Phi$.

Corollary 3.3 Let $(X, d, \preceq)$ be a complete ordered metric space, and let $f, g, T, S: X \rightarrow X$ be four mappings. Assume that there exist $\phi_{1}, \psi \in \Psi$ such that

$$
\begin{aligned}
\psi(d(f x, g y)) \leq & \psi\left(\max \left\{d(S x, T y), d(f x, S x), d(g y, T y), \frac{1}{2}(d(S x, g y)+d(f x, T y))\right\}\right) \\
& -\phi_{1}\left(\max \left\{d(S x, T y), d(f x, S x), d(g y, T y), \frac{1}{2}(d(S x, g y)+d(f x, T y))\right\}\right)
\end{aligned}
$$

holds for any two comparable elements $x, y \in X$. Suppose that $f, g, S$ and $T$ satisfy the following conditions: 
(1) $f X \subseteq T X$;

(2) $g X \subseteq S X$;

(3) $f$ is dominating and weak annihilator of $T$;

(4) $g$ is dominating and weak annihilator of $S$;

(5) $\{f, S\}$ and $\{g, T\}$ are weakly compatible;

(6) one of $f X, g X, S X$ and $T X$ is a closed subspace of $X$.

If $X$ satisfies the property $(\pi)$, then $f, g, S$ and $T$ have a common fixed point.

Proof By noting that

$$
\begin{aligned}
& \phi_{1}(\max \{d(S x, T y), d(S x, g y), d(f x, T y)\}) \\
& \quad \leq \phi_{1}\left(\max \left\{d(S x, T y), d(f x, S x), d(g y, T y), \frac{1}{2}(d(S x, g y)+d(f x, T y))\right\}\right),
\end{aligned}
$$

the proof follows from Corollary 3.2.

Jachymski [40] proved that some conditions for generalized contractions in (ordered) metric spaces are equivalent. By the aid of Lemma 1 [40], we have the following result.

Theorem 3.2 Let $f, g, S$ and $T$ be self-mappings on a partial ordered metric space $(X, d)$, and set

$$
M(x, y)=\max \left\{d(S x, T y), d(f x, S x), d(g y, T y), \frac{1}{2}(d(S x, g y)+d(f x, T y))\right\} .
$$

Then the following are equivalent:

(i) There exist $\alpha \in[0,1)$ and $\psi \in \Psi$ such that

$$
\psi(d(f x, g y)) \leq \alpha \psi(M(x, y))
$$

for all comparable elements $x, y \in X$.

(ii) There exist $\psi, \phi \in \Psi$ such that

$$
\psi(d(f x, g y)) \leq \psi(M(x, y))-\phi(M(x, y))
$$

for all comparable elements $x, y \in X$.

(iii) There exists a continuous nondecreasing function $\phi:[0,+\infty) \rightarrow[0,+\infty)$ such that $\phi(t)<t$ for all $t>0$ and for any $x, y \in X$,

$$
d(f x, g y) \leq \phi(M(x, y)) .
$$

Proof Set $D=\{(M(x, y), d(f x, g y)): x, y$ are two comparable elements in $X\}$. Then the proof follows from Lemma 1 of [40].

By the aid of Theorem 3.2 and Corollary 3.3, we have the following results. 
Theorem 3.3 Let $(X, d, \preceq)$ be a complete ordered metric space, and let $f, g, T, S: X \rightarrow X$ be four mappings. Assume that there exist $\psi \in \Psi$ and $k \in[0,1)$ such that

$$
\psi(d(f x, g y)) \leq k \psi\left(\max \left\{d(S x, T y), d(f x, S x), d(g y, T y), \frac{1}{2}(d(S x, g y)+d(f x, T y))\right\}\right)
$$

holds, for any two comparable elements $x, y \in X$. Suppose that $f, g, S$ and $T$ satisfy the following conditions:

(1) $f X \subseteq T X$;

(2) $g X \subseteq S X$;

(3) $f$ is dominating and weak annihilator of $T$;

(4) $g$ is dominating and weak annihilator of $S$;

(5) $\{f, S\}$ and $\{g, T\}$ are weakly compatible;

(6) one of $f X, g X, S X$ and $T X$ is a closed subspace of $X$.

If $X$ satisfies the property $(\pi)$, then $f, g, S$ and $T$ have a common fixed point.

Theorem 3.4 Let $(X, d, \preceq)$ be a complete ordered metric space, and let $f, g, T, S: X \rightarrow$ $X$ be four mappings. Assume that there exists a continuous and nondecreasing function $\phi:[0,+\infty) \rightarrow[0,+\infty)$ with $\phi(t)<t$ for all $t>0$ such that

$$
d(f x, g y) \leq \phi\left(\max \left\{d(S x, T y), d(f x, S x), d(g y, T y), \frac{1}{2}(d(S x, g y)+d(f x, T y))\right\}\right)
$$

holds for any two comparable elements $x, y \in X$. Suppose that $f, g, S$ and $T$ satisfy the following conditions:

(1) $f X \subseteq T X$;

(2) $g X \subseteq S X$;

(3) $f$ is dominating and weak annihilator of $T$;

(4) $g$ is dominating and weak annihilator of $S$;

(5) $\{f, S\}$ and $\{g, T\}$ are weakly compatible;

(6) one of $f X, g X, S X$ and $T X$ is a closed subspace of $X$.

If $X$ satisfies the property $(\pi)$, then $f, g, S$ and $T$ have a common fixed point.

As a direct result of our theorems, we have the following result.

Corollary 3.4 Let $(X, d, \preceq)$ be a complete ordered metric space, and let $f, g, T, S: X \rightarrow X$ be four mappings. Assume that there exists $k \in[0,1)$ such that

$$
d(f x, g y) \leq k \max \left\{d(S x, T y), d(f x, S x), d(g y, T y), \frac{1}{2}(d(S x, g y)+d(f x, T y))\right\}
$$

holds for any two comparable elements $x, y \in X$. Suppose that $f, g, S$ and $T$ satisfy the following conditions:

(1) $f X \subseteq T X$;

(2) $g X \subseteq S X$;

(3) $f$ is dominating and weak annihilator of $T$;

(4) $g$ is dominating and weak annihilator of $S$;

(5) $\{f, S\}$ and $\{g, T\}$ are weakly compatible; 
(6) one of $f X, g X, S X$ and $T X$ is a closed subspace of $X$.

If $X$ satisfies the property $(\pi)$, then $f, g, S$ and $T$ have a common fixed point.

Remark 3.1 By using the method of Haghi et al. [33], its an easy matter to show that Theorem 2.1 is a consequence result of Corollary 3.4.

To support our results, we introduce the following example.

Example 3.1 On $X=\{0,1,2,3, \ldots\}$, define

$$
d: X \times X \rightarrow X, \quad d(x, y)= \begin{cases}0 & \text { if } x=y \\ \max \{x, y\} & \text { if } x \neq y\end{cases}
$$

We introduce a relation on $X$ by $x \preceq y$ if and only if $y \leq x$. Also, define $f, g, S, T: X \rightarrow X$ by the formulas

$$
f x=g x= \begin{cases}0 & \text { if } x \in\{0,1,2\} \\ 3 & \text { if } x \in\{3,4\} \\ x-2 & \text { if } x \geq 5\end{cases}
$$

and

$$
T x=S x= \begin{cases}0 & \text { if } x=0 \\ x+2 & \text { if } x \geq 1\end{cases}
$$

Consider $\psi:[0,+\infty) \rightarrow[0,+\infty), \psi(t)=t^{2}$ and $\phi:[0,+\infty) \times[0,+\infty) \times[0,+\infty) \rightarrow$ $[0,+\infty), \phi(t, s, u)=\max \{t, s, u\}$. Then, for every two comparable elements $x, y \in X$, we have

$$
\begin{aligned}
\psi(d(f x, f y)) \leq & \psi\left(\max \left\{d(T x, T y), d(f x, T x), d(f y, T y), \frac{1}{2}(d(T x, f y)+d(f x, T y))\right\}\right) \\
& -\phi(d(T x, T y), d(T x, f y), d(f x, T y)) .
\end{aligned}
$$

Proof Let

$$
M(x, y)=\max \left\{d(T x, T y), d(f x, T x), d(f y, T y), \frac{1}{2}(d(T x, f y)+d(f x, T y))\right\}
$$

and

$$
N(x, y)=\phi(d(T x, T y), d(T x, f y), d(f x, T y))=\max \{d(T x, T y), d(T x, f y), d(f x, T y)\} .
$$

Given $x, y \in X$, without loss of generality, we assume that $x \leq y$.

Now, we divide the proof into the following cases:

- CASE I: $x=y$. Here, we have $\psi(d(f x, f y))=0$ and get (3.12).

- CASE II: $x<y$ and $x, y \in\{0,1,2\}$. Here, $\psi(d(f x, f y))=0$, hence (3.12) holds.

- CASE III: $x \in\{0,1,2\}$ and $y=3$. Here, $f x=0, f y=3, T x \in\{0,3,4\}$ and $T y=5$. Thus, $d(f x, f y)=3, M(x, y)=5$ and $N(x, y)=5$. Since $9 \leq 25-5$, we obtain (3.12). 
- CASE IV: $x \in\{0,1,2\}$ and $y=4$. Here, $f x=0, f y=3, T x \in\{0,3,4\}$ and $T y=6$. Thus, $d(f x, f y)=3, M(x, y)=6$ and $N(x, y)=6$. Since $9 \leq 36-6$, we deduce (3.12).

- CASE v: $x \in\{0,1,2\}$ and $y \geq 5$. Here, $f x=0, f y=y-2, T x \in\{0,3,4\}$ and $T y=y+2$. Thus, $d(f x, f y)=y-2, M(x, y)=y+2$ and $N(x, y)=y+2$. Since $(y-2)^{2} \leq(y+2)^{2}-(y+2)$, we have (3.12).

- CASE VI: $x=3$ and $y=4$. Here, $f x=0, f y=3, T x=5$ and $T y=6$. Thus, $d(f x, f y)=3$, $M(x, y)=6$ and $N(x, y)=6$. Since $9 \leq 36-6$, we get (3.12).

- CASE VII: $x=3$ and $y \geq 5$. Here, $f x=3, f y=y-2, T x=5$ and $T y=y+2$. Thus, $d(f x, f y)=y-2, M(x, y)=y+2$ and $N(x, y)=y+2$. Since $(y-2)^{2} \leq(y+2)^{2}-(y+2)$, we have (3.12) and

$$
\begin{aligned}
& \psi(p(f x, g y)) \\
& \quad \leq e^{-1} \psi\left(\max \left\{p(S x, T y), p(f x, S x), p(g y, T y), \frac{1}{2}(p(S x, g y)+p(f x, T y))\right\}\right) .
\end{aligned}
$$

- CASE viII: $x=4$ and $y \geq 5$. Here, $f x=3, f y=y-2, T x=6$ and $T y=y+2$. Thus, $d(f x, f y)=y-2, M(x, y)=y+2$ and $N(x, y)=y+2$. Since $(y-2)^{2} \leq(y+2)^{2}-(y+2)$, we have (3.12) and (3.13).

- CASE IX: $y>x \geq 5$. Here, $f x=x-2, f y=y-2, T x=x+2$ and $T y=y+2$. Thus, $d(f x, f y)=y-2, M(x, y)=y+2$ and $N(x, y)=y+2$. Since $(y-2)^{2} \leq(y+2)^{2}-(y+2)$, we have (3.12) and (3.13).

Remark 3.2 Note that Example 3.1 satisfies all the hypotheses of Corollary 3.1. But Example 3.1 does not satisfy the hypotheses of Theorem 2.1.

\section{Conclusions}

In this paper, we proved some common fixed point theorems for four mappings $f, g, S$ and $T$ satisfying a nonlinear contraction in ordered metric spaces, where the mappings $f$ and $g$ are dominating and weak annihilators of the mappings $T$ and $S$, respectively. We utilized the techniques of Haghi et al. [33] to derive our main result, which is a generalization of the result of Shobkolaei et al. [38]. Also, we introduced an example to support the usability of our results.

Competing interests

The authors declare that they have no competing interests.

\section{Authors' contributions}

Both authors contributed equally and significantly in writing this article. Both authors read and approved the final manuscript.

\section{Author details}

'Department of Mathematics, Hashemite University, Zarqa, Jordan. ${ }^{2}$ Faculty of Applied Sciences, University Politehnica of Bucharest, 313 Splaiul Independenţei, Bucharest, 060042, Romania.

Received: 8 May 2013 Accepted: 28 August 2013 Published: 08 Nov 2013

\section{References}

1. Ran, ACM, Reurings, MCB: A fixed point theorem in partially ordered sets and some applications to matrix equations. Proc. Am. Math. Soc. 132(5), 1435-1443 (2004)

2. Nieto, JJ, Lopez, RR: Contractive mapping theorems in partially ordered sets and applications to ordinary differential equations. Order 22, 223-239 (2005)

3. Nieto, JJ, Lopez, RR: Existence and uniqueness of fixed point in partially ordered sets and applications to ordinary differential equations. Acta Math. Sin. 23(12), 2205-2212 (2007) 
4. O'Regan, D, Petruşel, A: Fixed point theorems for generalized contractions in ordered metric spaces. J. Math. Anal. Appl. 341(2), 241-1252 (2008)

5. Agarwal, RP, El-Gebeily, MA, O'Regan, D: Generalized contractions in partially ordered metric spaces. Appl. Anal. 87, 1-8 (2008)

6. Aghajani, A, Radenović, S, Roshan, JR: Common fixed point results for four mappings satisfying almost generalized (S,T)-contractive condition in partially ordered metric spaces. Appl. Math. Comput. 218, 5665-5670 (2012)

7. Aydi, H, Shatanawi, W, Postolache, M, Mustafa, Z, Tahat, N: Theorems for Boyd-Wong type contractions in ordered metric spaces. Abstr. Appl. Anal. 2012, Article ID 359054 (2012)

8. Aydi, H, Karapınar, E, Postolache, M: Tripled coincidence point theorems for weak $\varphi$-contractions in partially ordered metric spaces. Fixed Point Theory Appl. 2012, 44 (2012)

9. Cho, YJ, Rhoades, BE, Saadati, R, Samet, B, Shatanawi, W: Nonlinear coupled fixed point theorems in ordered generalized metric spaces with integral type. Fixed Point Theory Appl. 2012, 8 (2012)

10. Ćirić, L, et al:: Common fixed points of almost generalized contractive mappings in ordered metric spaces. Appl. Math. Comput. 217, 5784-5789 (2011)

11. Gholizadeh, L, Saadati, R, Shatanawi, W, Vaezpour, SM: Contractive mapping in generalized, ordered metric spaces with application in integral equations. Math. Probl. Eng. 2011, Article ID 380784 (2011)

12. Luong, NV, Thuan, N: Fixed point theorem for generalized weak contractions satisfying rational expressions in ordered metric spaces. Fixed Point Theory Appl. 2011, 46 (2011)

13. Radenović, S, Kadelburg, Z: Generalized weak contractions in partially ordered metric spaces. Comput. Math. Appl. 60, 1776-1783 (2010)

14. Nashine, HK, Samet, B: Fixed point results for mappings satisfying $(\phi, \psi)$-weakly contractive condition in partially ordered metric spaces. Nonlinear Anal. 74, 2201-2209 (2011)

15. Chandok, S, Postolache, M: Fixed point theorem for weakly Chatterjea-type cyclic contractions. Fixed Point Theory Appl. 2013, 28 (2013)

16. Shatanawi, W, Postolache, M: Common fixed point results of mappings for nonlinear contractions of cyclic form in ordered metric spaces. Fixed Point Theory Appl. 2013, 60 (2013)

17. Shatanawi, W, Al-Rawashdeh, A: Common fixed points of almost generalized $(\psi, \phi)$-contractive mappings in ordered metric spaces. Fixed Point Theory Appl. 2012, 80 (2012)

18. Shatanawi, W, Mustafa, Z, Tahat, N: Some coincidence point theorems for nonlinear contraction in ordered metric spaces. Fixed Point Theory Appl. 2011, 68 (2011)

19. Shatanawi, W, Samet, B: On $(\psi, \phi)$-weakly contractive condition in partially ordered metric spaces. Comput. Math. Appl. 62, 3204-3214 (2011)

20. Berinde, V: Iterative Approximation of Fixed Points. Springer, Berlin (2007)

21. Berinde, V: General constructive fixed point theorems for Ćirić-type almost contractions in metric spaces. Carpath. J. Math. 24(2), 10-19(2008)

22. Berinde, V: Approximating common fixed points of noncommuting almost contractions in metric spaces. Fixed Point Theory 11(2), 179-188 (2010)

23. Berinde, $\mathrm{V}$ : Common fixed point of noncommuting almost contractions in cone metric spaces. Math. Commun. 15 , 229-241 (2010)

24. Berinde, V: Common fixed points of noncommuting discontinuous weakly contractive mappings in cone metric spaces. Taiwan. J. Math. 14, 1763-1776 (2010)

25. Babu, GVR, Sandhya, ML, Kameswari, MVR: A note on a fixed point theorem of Berinde on weak contractions. Carpath. J. Math. 24, 8-12 (2008)

26. Berinde, V, Păcurar, M: Fixed points and continuity of almost contractions. Fixed Point Theory 9(1), 23-34 (2008)

27. Ćirić, L, et al.: Common fixed points of almost generalized contractive mappings in ordered metric spaces. Appl. Math. Comput. 217, 5784-5789 (2011)

28. Haghi, RH, Postolache, M, Rezapour, S: On T-stability of the Picard iteration for generalized $\varphi$-contraction mappings Abstr. Appl. Anal. 2012, Article ID 658971 (2012)

29. Olatinwo, MO, Postolache, M: Stability results for Jungck-type iterative processes in convex metric spaces. Appl. Math. Comput. 218(12), 6727-6732 (2012)

30. Samet, B, Vetro, C: Berinde mappings in orbitally complete metric spaces. Chaos Solitons Fractals (2011). doi:10.1016/j.chaos.2011.08.009

31. Shatanawi, W: Some fixed point results for a generalized $\psi$-weak contraction mappings in orbitally metric spaces. Chaos Solitons Fractals 45, 520-526 (2012)

32. Matthews, SG: Partial metric topology. Ann. N.Y. Acad. Sci. 728, 183-197 (1994)

33. Haghi, RH, Rezapour, S, Shahzad, N: Be careful on partial metric fixed point results. Topol. Appl. 160, 450-454 (2013)

34. Jungck, G: Common fixed points for noncontinuous nonself maps on nonmetric spaces. Far East J. Math. Sci. 4 , 199-215 (1996)

35. Abbas, M, Talat, N, Radenović, S: Common fixed points of four maps in partially ordered metric spaces. Appl. Math. Lett. 24, 1520-1526 (2011)

36. Shatanawi, W, Postolache, M: Coincidence and fixed point results for generalized weak contractions in the sense of Berinde on partial metric spaces. Fixed Point Theory Appl. 2013, 54 (2013)

37. Shatanawi, W, Pitea, A: Some coupled fixed point theorems in quasi-partial metric spaces. Fixed Point Theory Appl. 2013, $153(2013)$

38. Shobkolaei, $\mathrm{N}$, Sedghi, $\mathrm{S}$, Roshan, JR, Altun, I: Common fixed point of mappings satisfying almost generalized (S,T)-contractive condition in partially ordered partial metric spaces. Appl. Math. Comput. 219, 443-452 (2012)

39. Khan, MS, Swaleh, M, Sessa, S: Fixed point theorems by altering distances between the points. Bull. Aust. Math. Soc 30, 1-9 (1984)

40. Jachymski, J: Equivalent conditions for generalized contractions on (ordered) metric spaces. Nonlinear Anal. 74, 768-774 (2011) 
10.1186/1687-1812-2013-271

Cite this article as: Shatanawi and Postolache: Common fixed point theorems for dominating and weak annihilator mappings in ordered metric spaces. Fixed Point Theory and Applications 2013, 2013:271

Submit your manuscript to a SpringerOpen ${ }^{\circ}$ journal and benefit from:

- Convenient online submission

- Rigorous peer review

- Immediate publication on acceptance

Open access: articles freely available online

- High visibility within the field

- Retaining the copyright to your article

Submit your next manuscript at $\gg$ springeropen.com 